\title{
Contributions of polymorphisms in miR146a, miR196a, and miR499 to the development of hepatocellular carcinoma
}

\author{
L.H. Zhang, ${ }^{1,2}$, B.B. Hao ${ }^{1}$, C.Y. Zhang ${ }^{1}$, X.Z. Dai ${ }^{1}$ and F. Zhang ${ }^{1}$ \\ ${ }^{1}$ Liver Transplantation Center, \\ First Affiliated Hospital of Nanjing Medical University, Nanjing, Jiangsu, China \\ ${ }^{2}$ General Surgery Department, Taixing People's Hospital of Yangzhou University, \\ Jiangsu, China \\ Corresponding author: F. Zhang \\ E-mail: zhangfengzf41@163.com \\ Genet. Mol. Res. 15 (3): gmr.15038582 \\ Received February 29, 2016 \\ Accepted May 5, 2016 \\ Published September 9, 2016 \\ DOI http://dx.doi.org/10.4238/gmr.15038582
}

Copyright $(2016$ The Authors. This is an open-access article distributed under the terms of the Creative Commons Attribution ShareAlike (CC BY-SA) 4.0 License.

ABSTRACT. Hepatocellular carcinoma is one of the most common
malignant tumors worldwide; it is estimated that there were 782,000
new cases in 2012. MicroRNAs (miRNAs) play an important role
in carcinogenesis by regulating oncogenes and tumor suppressors.
We investigated the role of miR-146a, miR-196a2, and miR-499
polymorphisms in the risk of hepatocellular carcinoma in a Chinese
population. Hepatocellularcarcinomapatients (175) and healthy controls
(302) were recruited between April 2013 and March 2015. Genotype
analysis of miR-146a, miR-196a2, and miR- 499 polymorphisms
was carried out by polymerase chain reaction-restriction fragment
length polymorphism. There was a significant difference between
the genotype distribution of miR-196a2 in hepatocellular carcinoma
patients and controls $\left(\chi^{2}=17.23, \mathrm{P}<0.001\right)$. CG and GG miR-146a 
genotypes significantly elevated the risk of hepatocellular carcinoma compared with the CC genotype, with adjusted ORs (95\%CI) of 3.05 (1.07-8.70) and 4.96 (1.64-14.97), respectively. In the recessive model, the CG + GG genotype had a 3.75-fold risk of hepatocellular carcinoma compared with the CC genotype, with an adjusted OR $(95 \% \mathrm{CI})$ of 3.75 (1.39-10.11). However, no significant association was observed between miR-196a2 and miR-499 variants and risk of hepatocellular carcinoma in the co-dominant, dominant, and recessive models. The miR-146a polymorphism is a $\mathrm{G}$ to $\mathrm{C}$ substitution that causes a mismatch in the stem-loop of miRNA, which influences how the expression and transcriptional regulation of miRNA affects its target genes. Our study revealed that the GG and CG genotypes of miR-146a increased the risk of hepatocellular carcinoma in the Chinese population.

Key words: miR-146a; miR-196a2; miR-499; Polymorphism; Hepatocellular carcinoma

\section{INTRODUCTION}

Hepatocellular carcinoma is one of the most common malignant tumors worldwide; it is estimated that there were 782,000 new cases in $2012(5.6 \%$ of the total number of new hepatocellular carcinoma cases). More than $80 \%$ of cases occur in developing countries, with half arising in China (International Agency for Research on Cancer, 2012). The etiology of the disease has been widely studied, and previous research has demonstrated that many environmental and lifestyle factors, such as hepatitis $\mathrm{B} / \mathrm{C}$ virus infection, aflatoxins, long-term alcohol consumption and liver cirrhosis (Nguyen et al., 2009; Liu et al., 2012; Niu et al., 2016). Previous studies have demonstrated that many genetic variations contribute to the risk of developing hepatocellular carcinoma, including C-reactive protein, Holliday junction recognition protein (HJURP), epidermal growth factor 61A/G, and Ghrelin and FasL genes (Lao et al., 2015; Shen et al., 2015b; Zhang et al., 2015a; Huang et al., 2016; Khalifa et al., 2016).

Many studies on the association between microRNAs (miRNAs) and hepatocellular carcinoma have reported that miRNAs may play an important role in cancer initiation, progression, outgrowth, and drug resistance (Anwar et al., 2013; Wojcicka et al., 2014). miRNAs belongs to a class of non-coding small RNAs that comprise 18-23 nucleotides (Reddy, 2015). Previous studies have indicated that many miRNAs play an important role in carcinogenesis by regulating the expression of oncogenes and tumor suppressors (Zhang et al., 2015c; Zhao et al., 2016). Polymorphisms in miRNAs can alter the expression of proteins, thereby changing their function (Lu et al., 2016; Song et al., 2016). Many studies have reported an association between miR-146a, miR-196a2, and miR-499 genetic polymorphisms and the development of hepatocellular carcinoma, but the results are conflicting and inconclusive (Hu et al., 2013; Shan et al., 2013; Zhou et al., 2014; Li et al., 2015a). We carried out a study to investigate the association between miR-146a, miR-196a2, and miR-499 genetic variations and the risk of developing hepatocellular carcinoma in a Chinese population.

Genetics and Molecular Research 15 (3): gmr.15038582 


\section{MATERIAL AND METHODS}

\section{Subjects}

We used a case-control design for this study. A total of 175 newly confirmed hepatocellular carcinoma patients and 302 healthy control subjects were recruited from the First Affiliated Hospital of Nanjing Medical University between April 2013 and March 2015. Hepatocellular carcinoma patients were diagnosed by biopsy or resected tissues were examined by a pathologist. All diagnoses were confirmed for the purposes of the study. The exclusion criteria were patients who had a history of other malignant tumors or recurrent tumors.

Control subjects were recruited from the outpatient clinics or those attending the hospital for a regular health examination. The exclusion criteria for control subjects were those with malignant tumors, end-stage liver or renal diseases, or endocrine or digestive system diseases.

Detailed environmental, lifestyle, or clinical data were selected from medical records. The environmental and lifestyle characteristics included age, gender, cigarette smoking, alcohol consumption, and history of cancer in first relatives. The included clinical factors were alanine-transaminase (ALT), aspartate aminotransferase (AST), tumor node metastasis stage, and Child-Pugh classification. Cigarette smoking was classified into those that smoked (ever) and those that did not (never), and alcohol consumption was divided into those that drank (ever) and those that did not (never).

Each subject agreed to take part in the study and signed informed consent before recruitment. We obtained permission to conduct our study from the Ethics Committee of Jiangsu Provincial Hospital.

\section{DNA extraction and genotyping}

DNA was extracted from a peripheral venous blood sample $(5 \mathrm{~mL})$ obtained from each subject after enrollment into the study. The blood samples were put into tubes containing 0.5 $\mathrm{mg} / \mathrm{mL}$ ethylenediaminetetraacetic acid as an anticoagulant. Extraction of genomic DNA was carried out using a TIANGEN blood DNA kit (TIANGEN Biotech Co., Ltd., Beijing, China). Genotype analysis of miR-146a, miR-196a2, and miR-499 polymorphisms was carried out by polymerase chain reaction-restriction fragment length polymorphism (PCR-RFLP). The primers and restriction enzymes are shown in Table 1 and Figure 1. The PCR cycling conditions were as follows: an initial denaturation at $95^{\circ} \mathrm{C}$ for $10 \mathrm{~min} ; 35$ cycles of denaturation at $95^{\circ} \mathrm{C}$ for $30 \mathrm{~s}$, annealing at $62^{\circ} \mathrm{C}$ for $30 \mathrm{~s}$, and extension at $72^{\circ} \mathrm{C}$ for $30 \mathrm{~s}$; and a final extension at $72^{\circ} \mathrm{C}$ for 10 min. The PCR products of miR-146a, miR-196a2, and miR-499 were digested with SacI, MspI, and $B c l$ I restriction enzymes, respectively. The products were confirmed by electrophoresis on $1.5 \%$ agarose gel, and were observed under an ultraviolet instrument.

\section{Statistical analysis}

Comparisons of the subjects' characteristics were carried out using the chi-square $\left(\chi^{2}\right)$ test. Conformity of genotype frequencies to Hardy-Weinberg equilibrium was assessed by a goodness-of-fit chi-square test. The relationships between miR-146a, miR-196a2, and miR-499 polymorphisms and hepatocellular carcinoma risk were assessed using unconditional single

Genetics and Molecular Research 15 (3): gmr.15038582 
factor and binary logistic regression analysis, and the odds ratios (ORs) and corresponding $95 \%$ confidence intervals (95\%CIs) were obtained. Spearman interaction analysis was used to investigate the relationship between the miR-146a polymorphism and demographic and lifestyle data. The SPSS 16.0 software (SPSS Inc., Chicago, IL, USA) was used to analyze the results.

Table 1. Primers, restriction enzymes, and digestive products of miR-146a, miR-196a2, and miR-499 genes.

\begin{tabular}{l|l|l|l}
\hline Genes & SNP & Primers (5'-3') & Restriction enzymes \\
\hline miR-146a & rs2910164 & $\begin{array}{l}\text { CATGGGTTGTGTCAGTGTCAGAGCT } \\
\text { TGCCTTCTGTCTCCAGTCTTCCAA }\end{array}$ & SacI \\
\hline miR-196a2 & rs11614913 & $\begin{array}{l}\text { CCCCTTCCCTTCTCCTCCAGATA } \\
\text { CGAAAACCGACTGATGTAACTCCG }\end{array}$ & Ms I \\
\hline miR-499 & rs3746444 & $\begin{array}{l}\text { CAAAGTCTTCACTTCCCTGCCA } \\
\text { GATGTTTAACTCCTCTCCACGTGATC }\end{array}$ & BclI \\
\hline
\end{tabular}

$\mathrm{SNP}=$ single nucleotide polymorphism.

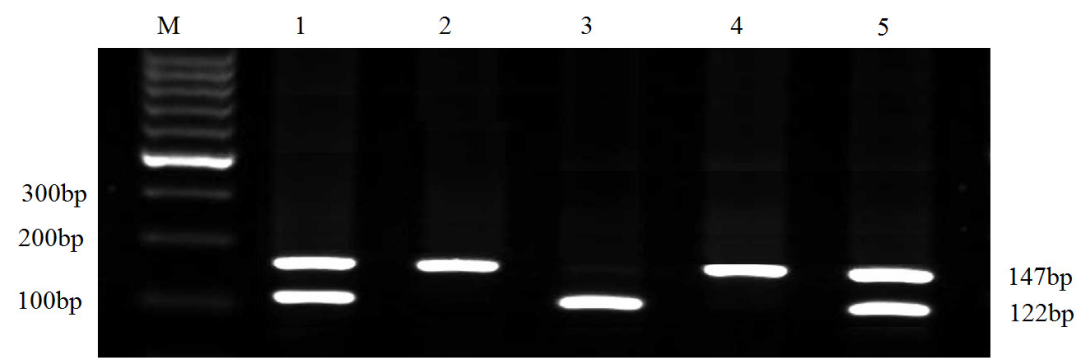

Figure 1. Agarose gel electrophoresis images for miR-146a. Lanes 2 and 4: G allele; Lanes 1, 3, and 5: C allele.

\section{RESULTS}

Comparisons of the subjects' characteristics are shown in Table 2. The mean ages of the hepatocellular carcinoma patients and control subjects were $56.13 \pm 7.60$ and 54.96 \pm 8.21 years, respectively. The hepatocellular carcinoma patients and control subjects were comparable in respect of age $(t=0.86, \mathrm{P}=0.356)$ and tobacco smoking $\left(\chi^{2}=0.62\right.$, $\mathrm{P}=0.431)$. However, the hepatocellular carcinoma group had more males $\left(\chi^{2}=9.16, \mathrm{P}\right.$ $=0.002)$, consumers of alcohol $\left(\chi^{2}=9.21, \mathrm{P}=0.002\right)$, individuals with a family history of cancer in first relatives $\left(\chi^{2}=26.93, \mathrm{P}<0.001\right)$, and had higher ALT $\left(\chi^{2}=416.86, \mathrm{P}<\right.$ $0.001)$ and $\operatorname{AST}(t=399.72, \mathrm{P}<0.001)$.

We then calculated the genotype distributions of miR-146a, miR-196a2, and miR499 between the two study groups, as shown in Table 3 . There was a significant difference between the genotype distribution of miR-196a2 between hepatocellular carcinoma patients and control subjects according to the results of the chi-square test $\left(\chi^{2}=17.23, \mathrm{P}\right.$ $<0.001)$, whereas no significant differences were found in the genotype frequencies of miR-196a2 $\left(\chi^{2}=0.51, \mathrm{P}=0.776\right)$ and miR-499 $\left(\chi^{2}=0.05, \mathrm{P}=0.976\right)$ between the two study groups. The genotype distributions of miR-146a, miR-196a2, and miR-499 were in agreement with the HWE in patients and controls.

Genetics and Molecular Research 15 (3): gmr.15038582 
Table 2. Subjects' demographic, lifestyle, and clinical data.

\begin{tabular}{|c|c|c|c|c|c|c|}
\hline Variables & Patients $(\mathrm{N}=175)$ & $\%$ & Controls $(\mathrm{N}=302)$ & $\%$ & $\chi^{2}$-test or $t$-test & $P$ value \\
\hline Age, years & $56.13 \pm 7.60$ & & $54.96 \pm 8.21$ & & 0.86 & 0.356 \\
\hline \multicolumn{7}{|l|}{ Gender } \\
\hline Males & 123 & 70.29 & 170 & 56.29 & & \\
\hline Females & 52 & 29.71 & 132 & 43.71 & 9.16 & 0.002 \\
\hline \multicolumn{7}{|c|}{ Tobacco smoking } \\
\hline Never & 115 & 65.71 & 209 & 69.21 & & \\
\hline Ever & 60 & 34.29 & 93 & 30.79 & 0.62 & 0.431 \\
\hline \multicolumn{7}{|c|}{ Alcohol consumption } \\
\hline Never & 87 & 49.71 & 193 & 63.91 & & \\
\hline Ever & 88 & 50.29 & 109 & 36.09 & 9.21 & 0.002 \\
\hline \multicolumn{7}{|c|}{ Family history of cancer } \\
\hline No & 142 & 81.14 & 289 & 95.70 & & \\
\hline Yes & 33 & 18.86 & 13 & 4.30 & 26.93 & $<0.001$ \\
\hline \multicolumn{7}{|l|}{ ALT, U/L } \\
\hline$<40$ & 5 & 2.86 & 294 & 97.35 & & \\
\hline$\geq 40$ & 170 & 97.14 & 8 & 2.65 & 416.86 & $<0.001$ \\
\hline \multicolumn{7}{|l|}{ AST, U/L } \\
\hline$<40$ & 6 & 3.43 & 289 & 95.70 & & \\
\hline$\geq 40$ & 169 & 96.57 & 13 & 4.30 & 399.72 & $<0.001$ \\
\hline \multicolumn{7}{|l|}{ TNM stage } \\
\hline I-II & 62 & 35.43 & & & & \\
\hline III-IV & 113 & 64.57 & & & & \\
\hline \multicolumn{7}{|c|}{ Child-Pugh classification } \\
\hline$\overline{\mathrm{A}}$ & 34 & 19.43 & & & & \\
\hline $\mathrm{B}$ & 70 & 40.00 & & & & \\
\hline$\overline{\mathrm{C}}$ & 71 & 40.57 & & & & \\
\hline
\end{tabular}

$\mathrm{ALT}=$ alanine-transaminase $;$ AST $=$ aspartate aminotransferase.

Table 3. Genotype distributions of miR-146a, miR-196a2, and miR-499.

\begin{tabular}{|c|c|c|c|c|c|c|c|c|}
\hline \multirow[t]{2}{*}{ SNPs } & \multirow[t]{2}{*}{ Patients $(\mathrm{N}=175)$} & \multirow[t]{2}{*}{$\%$} & \multirow[t]{2}{*}{ Controls $(\mathrm{N}=302)$} & \multirow[t]{2}{*}{$\%$} & \multirow[t]{2}{*}{$\chi^{2}$ test } & \multirow[t]{2}{*}{ P value } & \multicolumn{2}{|c|}{$\mathrm{P}$ for $\mathrm{HWE}$} \\
\hline & & & & & & & Patients & Controls \\
\hline \multicolumn{9}{|c|}{ miR-146a } \\
\hline $\mathrm{CC}$ & 52 & 29.71 & 137 & 45.36 & & & & \\
\hline $\mathrm{CG}$ & 86 & 49.14 & 135 & 44.70 & & & & \\
\hline GG & 37 & 21.14 & 30 & 9.93 & 17.23 & $<0.001$ & 0.90 & 0.70 \\
\hline \multicolumn{9}{|c|}{ miR-196a2 } \\
\hline TT & 65 & 37.14 & 122 & 40.40 & & & & \\
\hline TC & 85 & 48.57 & 138 & 45.70 & & & & \\
\hline $\mathrm{CC}$ & 25 & 14.29 & 42 & 13.91 & 0.51 & 0.776 & 0.74 & 0.77 \\
\hline \multicolumn{9}{|c|}{ miR-499 } \\
\hline TT & 115 & 65.71 & 197 & 65.23 & & & & \\
\hline $\mathrm{CT}$ & 49 & 28.00 & 87 & 28.81 & & & & \\
\hline $\mathrm{CC}$ & 11 & 6.29 & 18 & 5.96 & 0.05 & 0.976 & 0.08 & 0.05 \\
\hline
\end{tabular}

HWE $=$ Hardy-Weinberg equilibrium.

The results of logistic regression analysis of the association between miR-146a, miR196a2, and miR-499 polymorphisms and the risk of hepatocellular carcinoma are shown in Table 4. Using single factor logistic regression analysis, we found that only the miR-146a variant was correlated with the risk of developing hepatocellular carcinoma. We found that CG and GG genotypes of miR-146a significantly elevated the risk of hepatocellular carcinoma in comparison with the CC genotype, with adjusted ORs (95\%CI) of 3.05 (1.07-8.70) and 4.96 (1.64-14.97), respectively. In the recessive model, the CG + GG genotype had a 3.75-fold risk of

Genetics and Molecular Research 15 (3): gmr.15038582 
hepatocellular carcinoma in comparison with the CC genotype, with an adjusted OR $(95 \% \mathrm{CI})$ of 3.75 (1.39-10.11). However, no significant association was observed between miR-196a2 and miR-499 variants and the risk of hepatocellular carcinoma in the co-dominant, dominant, and recessive models. Using Spearman interaction analysis, no significant interaction was observed between the miR-146a polymorphism and age, gender, alcohol consumption, family history of cancer, ALT, or AST (Table 5).

Table 4. Association between miR-146a, miR-196a2, and miR-499 polymorphisms and hepatocellular carcinoma risk.

\begin{tabular}{|c|c|c|c|c|c|c|c|c|}
\hline & $\begin{array}{c}\text { Patients } \\
(\mathrm{N}=175)\end{array}$ & $\%$ & $\begin{array}{c}\text { Controls } \\
(\mathrm{N}=302)\end{array}$ & $\%$ & Crude OR $(95 \% \mathrm{CI})$ & P value & Adjusted OR $(95 \% \mathrm{CI})^{1}$ & P value \\
\hline \multicolumn{9}{|l|}{ miR-146a } \\
\hline \multicolumn{9}{|c|}{ Co-dominant } \\
\hline $\mathrm{CC}$ & 52 & 29.72 & 137 & 45.36 & 1.0 (Ref.) & & 1.0 (Ref.) & \\
\hline $\mathrm{CG}$ & 86 & 49.14 & 135 & 44.71 & $1.96(1.13-3.41)$ & 0.017 & $3.05(1.07-8.70)$ & 0.037 \\
\hline GG & 37 & 21.14 & 30 & 9.93 & $3.30(1.85-5.89)$ & 0.000 & $4.96(1.64-14.97)$ & 0.004 \\
\hline \multicolumn{9}{|l|}{ Dominant } \\
\hline $\mathrm{CC}$ & 52 & 29.72 & 137 & 45.36 & 1.0 (Ref.) & & 1.0 (Ref.) & \\
\hline $\mathrm{CG}+\mathrm{GG}$ & 123 & 70.28 & 165 & 54.64 & $1.97(1.33-2.93)$ & 0.001 & $2.06(0.96-4.42)$ & 0.065 \\
\hline \multicolumn{9}{|l|}{ Recessive } \\
\hline$\overline{C C}+\mathrm{CG}$ & 138 & 78.86 & 272 & 90.07 & 1.0 (Ref.) & & 1.0 (Ref.) & \\
\hline GG & 37 & 21.14 & 30 & 9.93 & $2.43(1.44-4.11)$ & 0.001 & $3.75(1.39-10.11)$ & 0.009 \\
\hline \multicolumn{9}{|l|}{ miR-196a2 } \\
\hline \multicolumn{9}{|c|}{ Co-dominant } \\
\hline TT & 65 & 37.14 & 122 & 40.40 & 1.0 (Ref.) & & 1.0 (Ref.) & \\
\hline $\mathrm{TC}$ & 85 & 48.57 & 138 & 45.70 & $1.20(0.66-2.17)$ & 0.549 & $0.87(0.28-2.69)$ & 0.810 \\
\hline $\mathrm{CC}$ & 25 & 14.29 & 42 & 13.90 & $1.00(0.56-1.78)$ & 1.000 & $0.94(0.29-2.99)$ & 0.911 \\
\hline \multicolumn{9}{|l|}{ Dominant } \\
\hline TT & 65 & 37.14 & 122 & 40.4 & 1.0 (Ref.) & & 1.0 (Ref.) & \\
\hline $\mathrm{TC}+\mathrm{CC}$ & 110 & 62.86 & 180 & 59.6 & $1.18(0.80-1.73)$ & 0.42 & $0.91(0.44-1.88)$ & 0.81 \\
\hline \multicolumn{9}{|l|}{ Recessive } \\
\hline $\mathrm{TT}+\mathrm{TC}$ & 150 & 85.71 & 260 & 86.1 & 1.0 (Ref.) & & 1.0 (Ref.) & \\
\hline $\mathrm{CC}$ & 25 & 14.29 & 42 & 13.9 & $1.06(0.61-1.81)$ & 0.85 & $0.88(0.30-2.54)$ & 0.88 \\
\hline \multicolumn{9}{|l|}{ miR-499 } \\
\hline \multicolumn{9}{|c|}{ Co-dominant } \\
\hline TT & 115 & 65.71 & 197 & 65.23 & 1.0 (Ref.) & & 1.0 (Ref.) & \\
\hline $\mathrm{CT}$ & 49 & 28 & 87 & 28.81 & $1.01(0.45-2.24)$ & 0.990 & $0.56(0.10-3.24)$ & 0.561 \\
\hline $\mathrm{CC}$ & 11 & 6.29 & 18 & 5.96 & $1.02(0.44-2.37)$ & 0.965 & $0.65(0.11-4.00)$ & 0.650 \\
\hline \multicolumn{9}{|l|}{ Dominant } \\
\hline TT & 115 & 65.71 & 197 & 65.23 & 1.0 (Ref.) & & 1.0 (Ref.) & \\
\hline $\mathrm{CT}+\mathrm{CC}$ & 60 & 34.29 & 105 & 34.77 & $0.98(0.66-1.45)$ & 0.90 & $0.82(0.38-1.76)$ & 0.609 \\
\hline \multicolumn{9}{|l|}{ Recessive } \\
\hline $\mathrm{TT}+\mathrm{CT}$ & 164 & 93.71 & 284 & 94.04 & 1.0 (Ref.) & & 1.0 (Ref.) & \\
\hline $\mathrm{CC}$ & 11 & 6.29 & 18 & 5.96 & $1.06(0.48-2.32)$ & 0.89 & $0.68(0.13-3.63)$ & 0.650 \\
\hline
\end{tabular}

${ }^{1}$ Adjusted for age, gender, alcohol consumption, family history of cancer, alanine-transaminase (ALT), and aspartate aminotransferase (AST); Ref $=$ Reference.

Table 5. Spearman interaction analysis for the relationship between the miR-146a polymorphism and demographic and lifestyle data.

\begin{tabular}{l|c|c}
\hline Variables & Spearman correlation coefficient & P value \\
\hline Age & 0.059 & 0.114 \\
\hline Gender & -0.041 & 0.212 \\
\hline Alcohol consumption & 0.065 & 0.084 \\
\hline Family history of cancer & 0.046 & 0.139 \\
\hline ALT & 0.053 & 0.114 \\
\hline AST & 0.056 & 0.093 \\
\hline
\end{tabular}

$\mathrm{ALT}=$ alanine-transaminase; $\mathrm{AST}=$ aspartate aminotransferase. 


\section{CONCLUSION}

In this study, we evaluated the relationship between miR-146a, miR-196a2, and miR499 genetic polymorphisms and hepatocellular carcinoma risk, and found that the CG and GG genotypes of miR-146a contributed to the pathogenesis of the disease.

The miR-146a polymorphism is a G-to-C substitution that leads to an amino acid sequence change that causes a mismatch in the stem-loop of miRNA. One previous in vivo study has indicated that the GG genotype of miR-146a is associated with a high expression level of mature miR-146a, and contributes to cell proliferation and colony formation in hepatocellular cancer cells (Xu et al., 2008), whereas the CC genotype elevates the expression level of mature miR-146a (Shen et al., 2008). Therefore, a polymorphism in miR-146a could influence the expression and transcriptional regulation of miRNA with regards to its target genes.

Previous studies have reported a correlation between miR-146a genetic polymorphism and the development of a variety of cancers, such as papillary thyroid cancer, esophageal squamous cell carcinoma, bladder cancer, gastric cancer, and lung cancer (Deng et al., 2015; Liu et al., 2015; Qi et al., 2015; Shen et al., 2015a; Sodhi et al., 2015; Wei et al., 2015; Zhang et al., 2015b). Zhang et al. (2015b) carried out a study in a Chinese population with 1238 papillary thyroid cancer patients and 1275 controls, and reported no significant association between the miR-146a polymorphism and the risk of papillary thyroid cancer in the Chinese population. Shen et al. (2015a) performed a case-control study in a Chinese population with 1400 esophageal squamous cell carcinoma patients and 2185 control subjects, and suggested that the miR-146a variant did not influence esophageal squamous cell carcinoma. Wei et al. (2015) carried out a meta-analysis of eight case-control studies, and reported that the miR146 a variant might marginally contribute to a reduced risk of gastric cancer, especially in Caucasians. Sodhi et al. (2015) carried out a study on 250 lung cancer cases and 255 healthy controls, and reported that the miR-146a variant was associated with an increased risk of lung cancer. Liu et al. (2015) carried out a meta-analysis on 15 case-control studies, and reported that the miR-146a polymorphism may increase the risk of colorectal cancer.

The authors of several epidemiologic studies have reported an association between the miR-146a variant and the development of hepatocellular carcinoma in a variety of populations, but their findings are conflicting and inconclusive (Xu et al., 2008; Akk1z et al., 2011; Zhang et al., 2011; Hu et al., 2013; Cong et al., 2014; Zhou et al., 2014; Li et al., 2015a,b; Qi et al., 2015; Yan et al., 2015). The authors of other studies have reported similar results. Xu et al. (2008) carried out a study on 433 males and 46 females with hepatocellular carcinoma and 504 control subjects (444 males and 60 females), and reported that the GG genotype of the miR-146a variant contributed to susceptibility to hepatocellular carcinoma. Cong et al. (2014) carried out a study on 206 hepatocellular carcinoma patients (55 females and 151 males) and 217 controls (157 females and 60 males) in a Chinese population, and indicated that the GG genotype of the miR-146a polymorphism influenced the development of hepatocellular carcinoma, especially in HBV-infected patients. Zhou et al. (2014) performed a study consisting of 166 hepatocellular carcinoma patients (55 females and 151 males) and 281 controls (157 females and 60 males), and reported that the GG genotype of miR-146a was associated with an increased risk of hepatocellular carcinoma in China. However, the authors of some studies have reported inconsistent results. Akk1z et al. (2011) carried out a study consisting of 222 subjects with hepatocellular carcinoma (178 males and 44 females) and 222 cancer-free control subjects (178 males and 44 females), and reported that the miR-

Genetics and Molecular Research 15 (3): gmr.15038582 
146a polymorphism was not associated with the development of hepatocellular carcinoma in a Turkish population (Akk1z et al., 2011). Zhang et al. (2011) carried out a study including 963 hepatocellular carcinoma patients and 829 healthy controls, and discovered that the miR146a variant did not affect susceptibility to hepatocellular carcinoma. Li et al. (2015a) carried out a case-control study in a Chinese population consisting of 184 hepatocellular carcinoma patients (126 males and 58 females) and 184 control subjects (126 males and 58 females), and discovered that the miR-146a variant did not appear to affect genetic susceptibility to hepatocellular carcinoma. Yan et al. (2015) carried out a study consisting of 274 hepatocellular carcinoma patients (61 females and 213 males) and 328 controls (120 females and 208 males), and reported no association between the miR-146a genetic variant and hepatocellular carcinoma risk in a Chinese population. In our study, we found that the miR-146a genetic polymorphism contributes to hepatocellular carcinoma risk, which is consistent with the results of previous studies. The discrepancies between these studies may have been caused by differences in ethnicity, patient and control selection, and sample size.

Two limitations of this study should also be considered. First, we examined the associations between miR-146a, miR-196a2, and miR-499 polymorphisms and hepatocellular carcinoma risk, but did not investigate the expression levels of the miRNAs or their ability to target their associated mRNAs and influence cancer risk. Second, the sample size of our study was relatively small, which may have reduced its statistical power to reveal differences between the two investigated groups. Further studies with large-scale sample sizes are needed to confirm our findings.

In conclusion, we observed that the GG and CG genotypes of miR-146a contributed to an increased risk of hepatocellular carcinoma in the Chinese population under investigation.

\section{Conflicts of interest}

The authors declare no conflict of interest.

\section{ACKNOWLEDGMENTS}

We thanks for the help from staffs in First Affiliated Hospital of Nanjing Medical University, and the staffs in our hospital help us to collect the blood samples for our analysis.

\section{REFERENCES}

Akkız H, Bayram S, Bekar A, Akgöllü E, et al. (2011). No association of pre-microRNA-146a rs2910164 polymorphism and risk of hepatocellular carcinoma development in Turkish population: a case-control study. Gene 486: 104-109. http://dx.doi.org/10.1016/j.gene.2011.07.006

Anwar SL, Albat C, Krech T, Hasemeier B, et al. (2013). Concordant hypermethylation of intergenic microRNA genes in human hepatocellular carcinoma as new diagnostic and prognostic marker. Int. J. Cancer 133: 660-670. http://dx.doi. org/10.1002/ijc. 28068

Cong N, Chen H, Bu WZ, Li JP, et al. (2014). miR-146a G>C polymorphisms and risk of hepatocellular carcinoma in a Chinese population. Tumour Biol. 35: 5669-5673. http://dx.doi.org/10.1007/s13277-014-1750-2

Deng S, Wang W, Li X and Zhang P (2015). Common genetic polymorphisms in pre-microRNAs and risk of bladder cancer. World J. Surg. Oncol. 13: 297. http://dx.doi.org/10.1186/s12957-015-0683-6

Huang W, Zhang H, Hao Y, Xu X, et al. (2016). A non-synonymous single nucleotide polymorphism in the HJURP gene associated with susceptibility to hepatocellular carcinoma among Chinese. PLoS One 11: e0148618. http://dx.doi. org/10.1371/journal.pone.0148618

Genetics and Molecular Research 15 (3): gmr.15038582 
Hu M, Zhao L, Hu S and Yang J (2013). The association between two common polymorphisms in MicroRNAs and hepatocellular carcinoma risk in Asian population. PLoS One 8: e57012. http://dx.doi.org/10.1371/journal. pone. 0057012

International Agency for Research on Cancer (2012). GLOBOCAN 2012: Estimated Cancer Incidence, Mortality and Prevalence Worldwide in 2012. Available at http://globocan.iarc.fr/Pages/fact_sheets_population.aspx. Accessed April 14, 2016.

Khalifa RH, Bahgat DM, Darwish HA and Shahin RM (2016). Significant association between FasL gene -844T/C polymorphism and risk to hepatocellular carcinoma in Egyptian patients. Immunol. Lett. 172: 84-88. http://dx.doi. org/10.1016/j.imlet.2016.02.007

Lao X, Ren S, Lu Y, Yang D, et al. (2015). Genetic polymorphisms of C-reactive protein increase susceptibility to HBVrelated hepatocellular carcinoma in a Guangxi male population. Int. J. Clin. Exp. Pathol. 8: 16055-16063.

Li D, Peng JJ, Tan Y, Chen T, et al. (2015a). Genetic variations in microRNA genes and susceptibility to hepatocellular carcinoma. Genet. Mol. Res. 14: 1926-1931. http://dx.doi.org/10.4238/2015.March.20.2

Li X, Li K and Wu Z (2015b). Association of four common SNPs in microRNA polymorphisms with the risk of hepatocellular carcinoma. Int. J. Clin. Exp. Pathol. 8: 9560-9566.

Liu XX, Wang M, Xu D, Yang JH, et al. (2015). Quantitative assessment of the association between genetic variants in microRNAs and colorectal cancer risk. Biomed. Res. Int. 2015: 276410.

Liu Y, Chang CC, Marsh GM and Wu F (2012). Population attributable risk of aflatoxin-related liver cancer: systematic review and meta-analysis. Eur. J. Cancer. 48: 2125-2136. http://dx.doi.org/10.1016/j.ejca.2012.02.009

Lu J, Gu H, Tang Q, Wu W, et al. (2016). Common SNP in hsa-miR-196a-2 increases hsa-miR-196a-5p expression and predisposes to idiopathic male infertility in Chinese Han population. Sci. Rep. 6: 19825. http://dx.doi.org/10.1038/ $\underline{\text { srep } 19825}$

Nguyen VT, Law MG and Dore GJ (2009). Hepatitis B-related hepatocellular carcinoma: epidemiological characteristics and disease burden. J. Viral. Hepat. 16: 453-463.http://dx.doi.org/10.1111/j.1365-2893.2009.01117.x

Niu J, Lin Y, Guo Z, Niu M, et al. (2016). The epidemiological investigation on the risk factors of hepatocellular carcinoma: a case-control study in Southeast China. Medicine (Baltimore). 95: e2758. http://dx.doi.org/10.1097/ MD.0000000000002758

Qi P, Wang L, Zhou B, Yao WJ, et al. (2015). Associations of miRNA polymorphisms and expression levels with breast cancer risk in the Chinese population. Genet. Mol. Res. 14: 6289-6296. http://dx.doi.org/10.4238/2015.June.11.2

Reddy KB (2015). MicroRNA (miRNA) in cancer. Cancer Cell Int. 15: 38. http://dx.doi.org/10.1186/s12935-015-0185-1

Shan YF, Huang YH, Chen ZK, Huang KT, et al. (2013). miR-499A $>\mathrm{G}$ rs3746444 and miR-146aG $>C$ expression and hepatocellular carcinoma risk in the Chinese population. Genet. Mol. Res. 12: 5365-5371. http://dx.doi. org/10.4238/2013.November.7.11

Shen F, Chen J, Guo S, Zhou Y, et al. (2015a). Genetic variants in miR-196a2 and miR-499 are associated with susceptibility to esophageal squamous cell carcinoma in Chinese Han population. Tumour Biol. [Epub ahead of print].

Shen J, Ambrosone CB, DiCioccio RA, Odunsi K, et al. (2008). A functional polymorphism in the miR-146a gene and age of familial breast/ovarian cancer diagnosis. Carcinogenesis 29: 1963-1966. http://dx.doi.org/10.1093/carcin/bgn172

Shen XF, Zeng XT, Jian ZY, Zhou M, et al. (2015b). Quantitative assessment of the effect of epidermal growth factor 61A/G polymorphism on the risk of hepatocellular carcinoma. Oncol. Lett. 10: 3199-3205.

Sodhi KK, Bahl C, Singh N, Behera D, et al. (2015). Functional genetic variants in pre-miR-146a and 196a2 genes are associated with risk of lung cancer in North Indians. Future Oncol. 11: 2159-2173. http://dx.doi.org/10.2217/ $\underline{\text { fon. } 15.143}$

Song ZS, Wu Y, Zhao HG, Liu CX, et al. (2016). Association between the rs11614913 variant of miRNA-196a-2 and the risk of epithelial ovarian cancer. Oncol. Lett. 11: 194-200.

Wei Y, Li L and Gao J (2015). The association between two common polymorphisms (miR-146a rs2910164 and miR196a2 rs11614913) and susceptibility to gastric cancer: a meta-analysis. Cancer Biomark. 15: 235-248. http://dx.doi. org/10.3233/CBM-150470

Wojcicka A, Swierniak M, Kornasiewicz O, Gierlikowski W, et al. (2014). Next generation sequencing reveals microRNA isoforms in liver cirrhosis and hepatocellular carcinoma. Int. J. Biochem. Cell Biol. 53: 208-217. http://dx.doi. org/10.1016/j.biocel.2014.05.020

Xu T, Zhu Y, Wei QK, Yuan Y, et al. (2008). A functional polymorphism in the miR-146a gene is associated with the risk for hepatocellular carcinoma. Carcinogenesis 29: 2126-2131. http://dx.doi.org/10.1093/carcin/bgn195

Yan P, Xia M, Gao F, Tang G, et al. (2015). Predictive role of miR-146a rs2910164 (C>G), miR-149 rs2292832 (T>C), miR-196a2 rs11614913 (T>C) and miR-499 rs3746444 ( $>$ C) in the development of hepatocellular carcinoma. Int. J. Clin. Exp. Pathol. 8: 15177-15183.

Genetics and Molecular Research 15 (3): gmr.15038582 
Zhang X, Zhai L, Rong C, Qin X, et al. (2015a). Association of ghrelin gene polymorphisms and serum ghrelin levels with the risk of hepatitis B virus-related liver diseases in a Chinese population. PLoS One 10: e0143069. http://dx.doi. org/10.1371/journal.pone.0143069

Zhang X, Gu Y, Liu X, Yu Y, et al. (2015b). Association of pre-miR-146a rs2910164 polymorphism with papillary thyroid cancer. Int. J. Endocrinol. 2015: 802562. http://dx.doi.org/10.1155/2015/802562

Zhang XW, Pan SD, Feng YL, Liu JB, et al. (2011). [Relationship between genetic polymorphism in microRNAs precursor and genetic predisposition of hepatocellular carcinoma]. Zhonghua Yu Fang Yi Xue Za Zhi. 45: 239-243.

Zhang Y, Huang F, Wang J, Peng L, et al. (2015c). MiR-15b mediates liver cancer cells proliferation through targeting BCL-2. Int. J. Clin. Exp. Pathol. 8: 15677-15683.

Zhao X, Zhu D, Lu C, Yan D, et al. (2016). MicroRNA-126 inhibits the migration and invasion of endometrial cancer cells by targeting insulin receptor substrate 1. Oncol. Lett. 11: 1207-1212.

Zhou B, Dong LP, Jing XY, Li JS, et al. (2014). Association between miR-146aG $>C$ and miR-196a2C $>$ T polymorphisms and the risk of hepatocellular carcinoma in a Chinese population. Tumour Biol. 35: 7775-7780. http://dx.doi. org/10.1007/s13277-014-2020-z

Genetics and Molecular Research 15 (3): gmr.15038582 